\title{
A Bio-Inspired Amplification Cascade for the Detection of Rare Cancer Cells
}

\author{
Curzio Rüegg ${ }^{\star a}$, Corine Reis ${ }^{a}$, Sarah Rafiee ${ }^{a}$, Laura Rodriguez-Lorenzo ${ }^{\text {ab }}$, Jonathan List ${ }^{b}$, Barbara \\ Rothen-Rutishauser ${ }^{b}$ Michael Mayer ${ }^{b}$, and Alke Petri-Fink ${ }^{b}$
}

\begin{abstract}
The main cause of cancer-related death is due to cancer cell spreading and formation of secondary tumors in distant organs, the so-called metastases. Metastatic cancer cells are detectable in the blood of cancer patients as circulating tumor cells (CTC) and may be exploited for prognostic and monitoring purposes, including in breast cancer. Due to their very low frequency, however, their quantitative detection remains a challenge in clinical practice. Nature has developed mechanisms to amplify rare biological events or weak signals, such as intracellular signaling pathways, cytokine networks or the coagulation cascades. At the National Center for Competence in Research (NCCR) in Bio-Inspired Materials we are coupling gold nanoparticle-based strategies with fibrinogen and DNA bio-inspired amplification cascades to develop an in vitro test to specifically and sensitively detect CTCs in patients' blood. In this article, we describe the biological context, the concept of bio-inspired amplification, and the approaches chosen. We also discuss limitations, open questions and further potential biomedical applications of such an approach.
\end{abstract}

Keywords: Amplification · Breast cancer · Fibrin · Hybridization · in vitro diagnostic · Nanoparticle

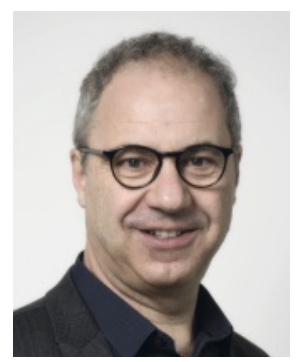

Curzio Rüegg studied medicine and trained in immunology, cell and molecular biology in Basel, Zürich and San Francisco. From 1993 to 2010 he headed the Division of Experimental Oncology at University Hospital and University of Lausanne (CHUV/UNIL) and was affiliated group leader at the Swiss Institute for Experimental Cancer Research (ISREC) in Lausanne. In 2010 he was appointed Full Professor and Chair of Pathology at the University of Fribourg and rotating department head. Since 2014 he is deputy-director of the NCCR program in Bio-Inspired Materials. He was and is member of numerous scientific committees at national and international institutions, including SFNS, SKL, UICC, INSERM, DFG, CRUK, ESO, SENDO. He co-organized international scientific conferences in the field of cancer and vascular biology. His research interest currently focuses on experimental and translational oncology in breast cancer, particularly on unravelling mechanisms of cancer progression, metastasis and resistance to therapy, with the long-term goal to develop innovative strategies in cancer therapy. He co-founded two start-up companies to develop a blood test for the detection of colorectal cancer that he conceived and is now on the market.

\section{Introduction}

\subsection{Breast Cancer}

Breast cancer remains the main cause of cancer-related mortality for women in industrialized countries. ${ }^{[1]}$ The development of therapy-resistant metastases in vital organs, in particular liver, lung and brain, is the ultimate cause of death in relapsing patients. ${ }^{[2]}$
Breast cancer prognosis and therapy are largely determined by the biological and molecular characteristics of the tumor. Three clinically relevant biological subtypes of breast cancer have been defined: Estrogen/Progesterone Receptor positive $\left(\mathrm{ER}^{+} / \mathrm{PR}^{+}\right)$, Human Epidermal growth factor Receptor 2 (HER2) amplified (HER2 ${ }^{+}$) and triple negative (i.e. $\mathrm{ER}^{-}, \mathrm{PR}^{-}$and $\mathrm{HER} 2^{-}$) breast cancers (TNBC). Molecular subtypes (Luminal A/B, HER2 ${ }^{+}$, basal-like) that overlap largely, but not fully with the biological subtypes, have been defined based on gene expression profiling. ${ }^{[3]}$ Early detection, better surgery and adjuvant treatments, in particular radiotherapy, antiestrogen therapies for $\mathrm{ER}^{+}$tumors (e.g. tamoxifen), and anti-HER2 treatments (e.g. trastuzumab) for HER $2^{+}$tumors, have improved survival by about $30 \%$ over the past 30 years. ${ }^{[4]}$ For TNBC there are still no molecular targets and radio- and chemotherapies are standard of care..$^{[5]}$ The rationale for administering adjuvant therapy is to prevent relapses by eradicating disseminated tumor cells (DTC) or micro-metastases, that were unapparent at time of diagnosis.

\subsection{Cancer Metastasis}

Metastasis formation involves four main steps ${ }^{[6]}$ (i.e. metastatic cascade): i) egress of cancer cells from the primary tumor and ingress into the lymphatic and/or blood vasculature; ii) dissemination through the blood circulation; iii) seeding and iv) colonization and metastatic outgrowth in distant organs. Molecules governing breast cancer metastasis to bone, lung and brain have been reported. ${ }^{[7]}$ Survival in the secondary tissue and colonization are emerging as the most critical and rate-limiting step in metastasis formation. While normal cells are unable to survive outside their tissue of origin, DTCs can 'adapt' to the novel microenvironment through a combination of acquired genetic characteristics, altered gene expression and complementary host-derived cues. ${ }^{[8]}$ As of today, there are no effective therapies to cure metastatic cancer.

\footnotetext{
${ }^{*}$ Correspondence: Prof. C. Rüegga

E-mail: curzio.ruegg@unifr.ch

aPathology, Department of Oncology, Microbiology and Immunology, Faculty of Science and Medicine, University of Fribourg, Per 17, Chemin du Musée 18 


\subsection{Circulating Tumor Cells (CTCs) and their Detection}

Circulating tumor cells are present in the blood of cancer patients, and numerous studies have demonstrated their diagnostic and prognostic relevance in multiple cancers including breast cancers. ${ }^{[9]}$ In general, the frequency of CTCs correlates with tumor burden and disease progression, although it can greatly differ across different cancers and between patients. Characterization of CTCs may contribute to understand molecular tumor evolution and metastatic progression. ${ }^{[10]}$ The detection and characterization of CTCs, however, remain technically challenging, because of their low frequency (as low as 1 CTC in $10^{7}-10^{8}$ nucleated blood cells), and the lack of universal markers. ${ }^{[11]}$ Thus, high sensitivity and specificity are key for optimal CTC detection. To this end many technologies have been developed, ${ }^{[12]}$ but only one, based on antibody-mediated magnetic cell sorting coupled with cellular staining, has been approved by the FDA for clinical use: CellSearch from Veridex (www.cellsearchctc. com). ${ }^{[13]}$ Magnetically enriched cells can be further analyzed by multiplexed reverse transcription polymerase chain reaction (RTPCR) to identify tumor-associated mRNAs. ${ }^{[14]}$ Immunological detection is complicated by the epithelial-to-mesenchymal transition (EMT) plasticity of CTC, whereby more aggressive cells lose expression of epithelial markers used for their identification, such as the Epithelial Cell Adhesion Molecule (EpCAM). ${ }^{[15]}$ Additional techniques have been proposed ${ }^{[12,16]}$ based on physical characteristics, including size and density properties, ${ }^{[17]}$ electrostatic features, ${ }^{[18]}$ microfluidic ${ }^{[19]}$ and lab-on-a-chip[20] platforms. These approaches can be coupled with immunostaining, imaging-based identification, molecular or biological characterization..$^{[21]}$

\subsection{Nanomaterial-based Approaches to Detect CTCs}

In an effort to improve currently available technologies for targeting and capturing CTCs, nanomaterials have increasingly gained attention as they offer unique physicochemical features compared to bulk materials, and can be modified for multiplexed detection and targeting. ${ }^{[22]}$ Many types of nanomaterials and approaches have been explored, ${ }^{[23]}$ including liposomes, polymeric nanofibers, ${ }^{[24]}$ nanowires, ${ }^{[25]}$ dendrimers and stimuli-responsive polymers, ${ }^{[23,26]}$ magnetic nanoparticles (MNPs), ${ }^{[23,26]}$ gold nanoparticles (AuNPs), ${ }^{[27]}$ quantum dots, ${ }^{[28]}$ graphenes and graphene oxides, ${ }^{[18 b]}$ and nano-velcro. ${ }^{[29]}$ Two well-studied nanoparticles used in nanomedicine are MNPs and AuNPs, both of which can be derivatized to specifically bind to CTCs in vivo or in vitro. MNPs, such as superparamagnetic iron oxide, can be used to separate cells by applying an external magnetic field.[23] The FDA-approved CellSearch system, as well as the AdnaTest, another commercialized approach, are based on cell capture through immunomagnetic nanoparticles coupled to an antibody to EpCAM, in combination with a tumor specific marker (e.g. HER2 or Mucin-1/MUC-1). ${ }^{[30]}$ Compared to MNPs, AuNPs offer the important advantage of a preeminent surface plasmon resonance peak giving rise to a sharp and intense absorbance band in the visible-near infrared range for direct detection. ${ }^{[31]}$ By changing environmental behavior around the particles (e.g. by interaction AuNP-cell, AuNP-protein), or the level of nanoparticle-nanoparticle interaction it is possible to modify spectral properties thereby facilitating detection. For example, Rauta et al. developed a platform for CTC detection and enumeration by the conjugation of hyaluronic acid (which binds specifically to CD44 molecules expressed on CTCs) to AuNPs. After binding to CD44 expressing cells, a color change from pink to purple occurs, along with a peak shift from from $521 \mathrm{~nm}$ to $559 \mathrm{~nm}$, which can be easily detected. The general strategy also allows for the separation of cells of interest by differential centrifugation, and subsequent culture for further experiments. ${ }^{[27]}$

\subsection{Bio-inspired Amplifications}

The above approaches, however, have one common limitation, which is the weak signal once the particles have bound to the target cells. We looked for inspiration in Nature to overcome this limitation. In order to maintain homeostasis and respond to stressors and damages, multicellular organisms coordinate complex cellular and molecular events between and within organs, tissues and cells. Cell-cell communication and effector functions are mainly mediated by soluble molecules, such as hormones (e.g. cortisol), growth factors (e.g. epidermal growth factor EGF) or cytokines (e.g. tumor necrosis factor TNF). Intracellular communication involves the rapid generation of small messenger molecules (e.g. cyclic adenosine monophosphate cAMP), modification of larger molecules (e.g. phosphorylation) and formation of macromolecular complexes (e.g. transcription factors). As the eliciting signals are often rare or weak (e.g. few ligand molecules or few receptors), a common feature of these signaling events is their cascade-like nature allowing the rapid propagation and amplification of the incipient signals into vigorous responses. The multi-step, cascade-like character also allows to apply multiple check-points to modulate the response. Intracellular signaling from a cell-surface receptor to the nucleus is a typical example of how Nature uses a multistep amplification cascade to induce a robust cellular response from rare biochemical events. ${ }^{[32]}$ The process of coagulation initiated by microscopic cellular, vascular or tissue lesions and leading to the formation of a macroscopic insoluble clot from soluble proteins as response to injury, is essential to the survival of vertebrates and is based on the principle of a cascadelike amplification. ${ }^{[33]}$ Similarly, the complement system consists of soluble components that once activated generate macromolecular pore-forming, cytotoxic complexes at the cell surface (Fig. 1). ${ }^{[34]}$ As a matter of fact, the principle of the process of inflammation itself is based on a complex sensing/amplification/effector network.

Within the NCCR Bio-Inspired Materials center (http://bioinspired-materials.ch/) we devised a project aimed at detecting CTCs in vitro, by combining an AuNP-based approach with a bio-inspired amplification system. The ultimate goal of this interdisciplinary project is to establish a simple, highly sensitive, specific, robust test to detect and quantify rare CTCs in patients' whole blood or leukocyte-rich plasma as an alternative, or complement to existing tests.

\section{Targeting Breast Cancer Cells with AuNP Combined with Bio-Inspired Amplification Systems}

\subsection{Nanoparticles Targeting HER2 Breast Cancer}

HER2 is a cell surface tyrosine kinase receptor that promotes cell survival, proliferation and migration. HER2 is overexpressed in a subset of breast cancer where it acts as an oncogenic driver. ${ }^{[35]}$ The anti-HER2 antibody trastuzumab has shown significant therapeutic activity and is currently routinely used to treat HER2 ${ }^{+}$cancers. ${ }^{[36]}$ HER2 has also been explored for purposes of imaging or targeted drug delivery to HER2 $2^{+}$tumors using anti-HER2 antibodies, aptamers, or peptides conjugated to organic or inorganic nanoparticles such as carbon nanotubes, ${ }^{[37]}$ quantum dots, ${ }^{[38]}$ chitosan, ${ }^{[39]}$ human serum albumin, ${ }^{[40]}$ iron oxide, ${ }^{[41]}$ silica ${ }^{[42]}$ and AuNPs. ${ }^{[43]}$ AuNPs have become increasingly popular in biomedical applications due to their excellent biocompatibility, unique optical properties, size and shape tunability, ease of functionalization and FDA approval for prospective human use. ${ }^{[44]}$ Polyethylene glycol (PEG)-coated silica-gold nanoshells (AuroLase; Nanospectra Biosciences) were tested in patients in a clinical trial (NCT01679470, www.clinicaltrials.gov) for thermal ablation of solid primary and/or metastatic lung tumors. ${ }^{[45]}$

One of the reasons for the slow translation of engineered NPs into clinical applications, is the synthetic challenge of creating highly engineered multifunctional NPs with high targeting efficiency, strong optical and scattering imaging properties and robust activity.[44c,46] We recently designed and established multifunctional $50 \mathrm{~nm}$ AuNPs with enhanced anti-biofouling and targeting properties. AuNPs were functionalized with PEG to decrease non-specific protein adsorption and enhance colloidal stability. The AuNPs were robustly charac- 


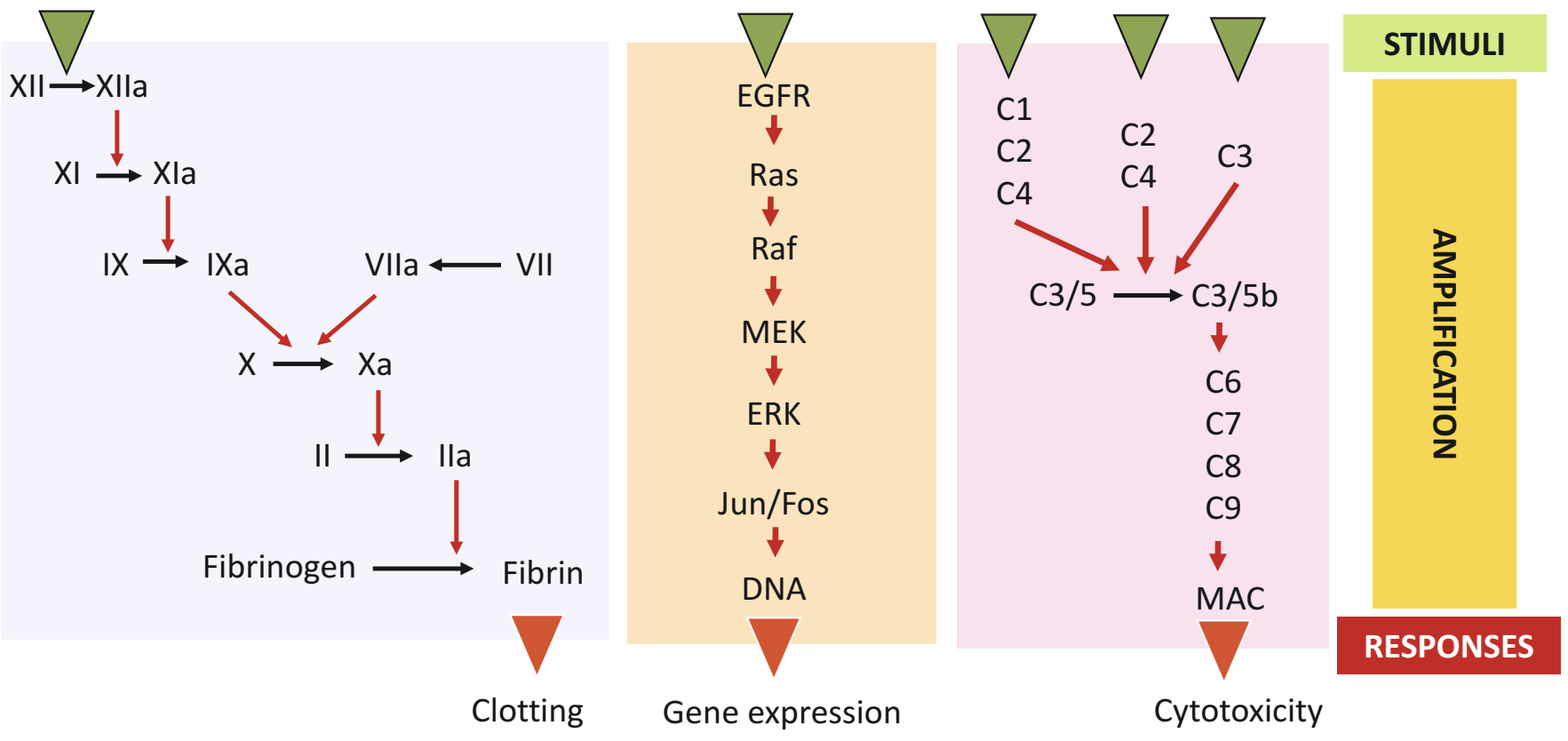

Fig. 1. Examples of amplification cascades in biological systems. Plasma coagulation, intracellular signaling and the complement system. All systems share a common principle: initiation by rare stimuli, rapid cascade-like activation of molecules leading to signal propagation and amplification, and robust responses.

terized in complex media and remained colloidally stable. AuNPs were bioconjugated to the anti-HER2 antibody trastuzumab under conditions of controlled or random orientation. Binding activity was maintained upon conjugation and optimal trastuzumab orientation resulted in effective, HER2-specific cellular targeting. These multifunctional NPs exhibited excellent physicochemical stability, strong affinity and high specificity for HER2-positive cells, while showing stealth-like behavior toward HER2-negative cells. ${ }^{[47]}$

\subsection{Coagulation Cascade-based Amplification}

The coagulation system is a balanced process consisting of a cascade of more than two dozens of enzyme activation events, where serine proteases activate the proteins of the next step of the cascade via limited proteolysis. Two pathways can trigger the cascade: the 'Extrinsic or Tissue Factor Pathway' and the 'Intrinsic or Contact Pathway'. ${ }^{[48]}$ Both of them have a common pathway at the end of the cascade, where $\mathrm{fXa}$, along with its cofactor fVa, plays a pivotal role of bursting the activation of thrombin, the last serine protease in the cascade. Thrombin will then proteolytically cleave fibrinogen $\alpha$ and $\beta$ subunits at their amino terminus resulting in the polymerization of fibrinogen into fibrin and platelets activation, thereby forming a fibrin clot. ${ }^{[49]}$ In our NCCR project, the cascade is activated by a first AuNP nanoparticle (NP1) that, upon antiHER 2 antibody-directed binding to HER2 positive breast cancer cells, enzymatically activates the coagulation cascade to generate fibrin at the cell surface, to which a second AuNP (NP2) carrying a fluorescent reporter system is targeted by antibodies or peptides to fibrin (Fig. 2A). The aim of this approach is to allow rapid and robust identification of CTCs among blood leucocytes as an in vitro diagnostic test. The rationale to use AuNPs rather than antibodies alone, is to confer multivalency and robustness to the system. The coagulation cascade-based model has provided proof of principle evidence that the amplification cascade approach is feasible to specifically and sensitively detect cancer cells (Fig. 2B). However, experiments also revealed some limitations of this approach, in particular stability and reproducibility, which are
A

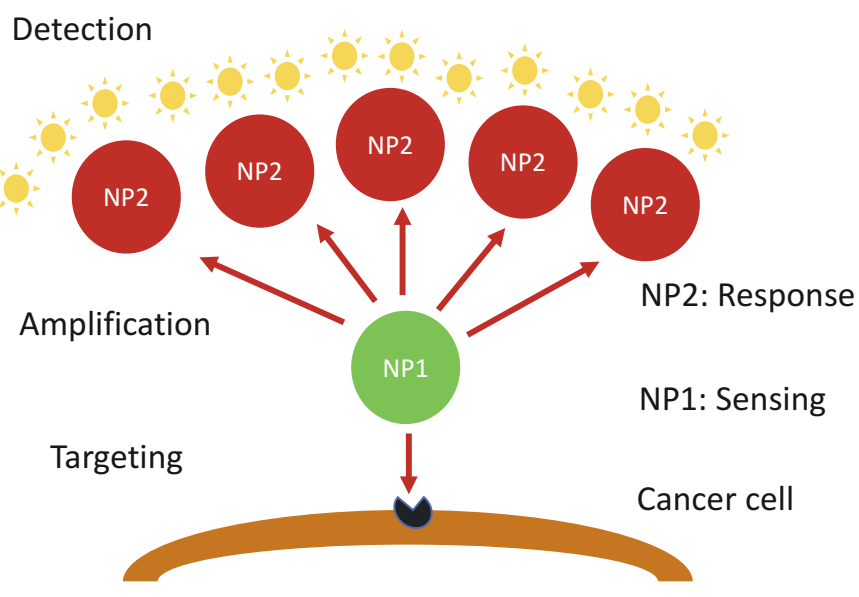

B

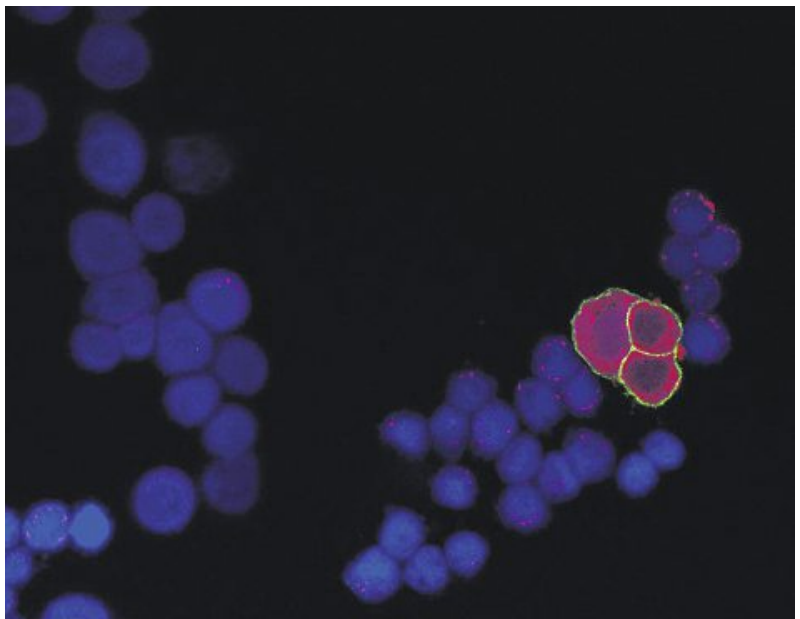

Fig. 2. A) Targeting/amplification concept. NP1 is targeted to the cell and initiates the amplification cascade, which attracts NP2. NP2 carry out the desired effect; B) Proof-of-concept experiment showing the specificity and sensitivity of the approach. HER2- cells showing signal only for nuclear Dapi staining (blue), while HER2+ cells are positive for AnNP1 (green) and AuNP2 (magenta) binding to polymerized fibrin. 
potentially problematic for a clinical test. Besides improving this approach, we started looking for alternative approaches based on synthetic cascades.

\subsection{DNA-based Amplification Cascade}

One of these alternatives is an amplification cascade based on programmable DNA reaction circuits. We employ a DNA hybridization chain reaction $(\mathrm{HCR})^{[50]}$ consisting of metastable DNA oligonucleotide hairpins that, once 'activated' by an initiator oligonucleotide, will switch structure to self-assemble into amplification polymers attaining high signal-to-background ratio with specific localization. ${ }^{50]}$ The HCR amplifier mechanism employs two DNA hairpin molecules $(\mathrm{H} 1$ and $\mathrm{H} 2)$ and an Initiator strand. Although one hairpin contains single stranded regions with complementary sequences within the loops of the second hairpin, hybridization is kinetically hampered as these segments are protected by their secondary structures. The energy necessary for driving an amplification reaction is stored within these single stranded loop regions. When hybridizing to the initiator via a toehold segment, the secondary structure of a first hairpin (H1) opens up, allowing a second hairpin (H2) to bind and release its secondary structure. Another binding site for $\mathrm{H} 1$ is presented, inducing a chain reaction that results in the assembly of a polymeric structure. By attaching fluorescent labels to each of the hairpins, proceeding polymerization will strongly amplify the signal of the initiator, attaining a strong signal localizing at the initiator site with a high signal-tobackground ratio (Fig. 3). [51] We have engineered the system to target HER $2^{+}$breast cancer cells using trastuzumab as a targeting moiety. Multiple different fluorescently labeled streptavidins are used for multivalent attaching to biotinylated trastuzumab, initiators and $\mathrm{H} 1$ and $\mathrm{H} 2$ for read out of the amplification signal. We are optimizing the hybridization conditions to obtain the best signalto-noise ratio and are developing branched DNA constructs for exponential signal amplification. Modular DNA attachment sides enable binding of different agents such as nanoparticles, therapeutics, fluorescent beads, and signal amplifying enzymes.

\section{Challenges and Open Questions}

While the coagulation cascade-based approach has provided proof of principle about the feasibility of the test, its translation into a robust product requires first solving outstanding questions. Two are particularly important. Firstly, how far can we push the sensitivity of the test? Can we detect one CTC among $10^{7}$ or $10^{8}$ cells? Such a high sensitivity implies a nearly zero background on normal cells and the capacity of 'not missing' these rare events. A one-step detection method, for example by flow cytometry, may not be appropriate, as this technique has its own limitations due to intrinsic background noise. A combination of cell enrichment and visual processing may be more suitable, though it requires one additional step. As fibrin-coated cells are larger than leukocytes, we are considering trapping them by filtration. ${ }^{[52]}$ Visual detection by fluorescence would add a second, orthogonal parameter improving specificity. Preliminary experiments indicate that this approach is feasible. Secondly, how can the system be adapted to detect other breast cancer subtypes? HER2 ${ }^{+}$CTCs, or CTCs with an epithelial phenotype are detected with antibodies to specific cell surface targets $(e . g$. HER2, MUC-1, EpCAM). However, this approach is more complicated for CTCs in TNBC, or CTCs that underwent EMT and for which there are no universal markers available. ${ }^{[15,53]}$ Combination of antibodies to other markers, such as CD24, CD44, CD133, CD49f, c-Met, CK8, ADAM8, CD146, TEM8, or CD47 have been attempted with alternate success. ${ }^{[54]}$ To circumvent these limitations, we are considering exploiting functional, rather than phenotypical features of cancer cells, in particular their increased cell surface proteolytic activity. AuNPs will be derivatized with substrates for proteases that once cleaved will unmask or activate cell binding molecules or enzymes.

\section{Bio-inspired Amplification Cascades to Kill Cancer Cells}

A further evolution of this principle would be the killing of CTCs or DTCs in conditions of minimal residual disease after

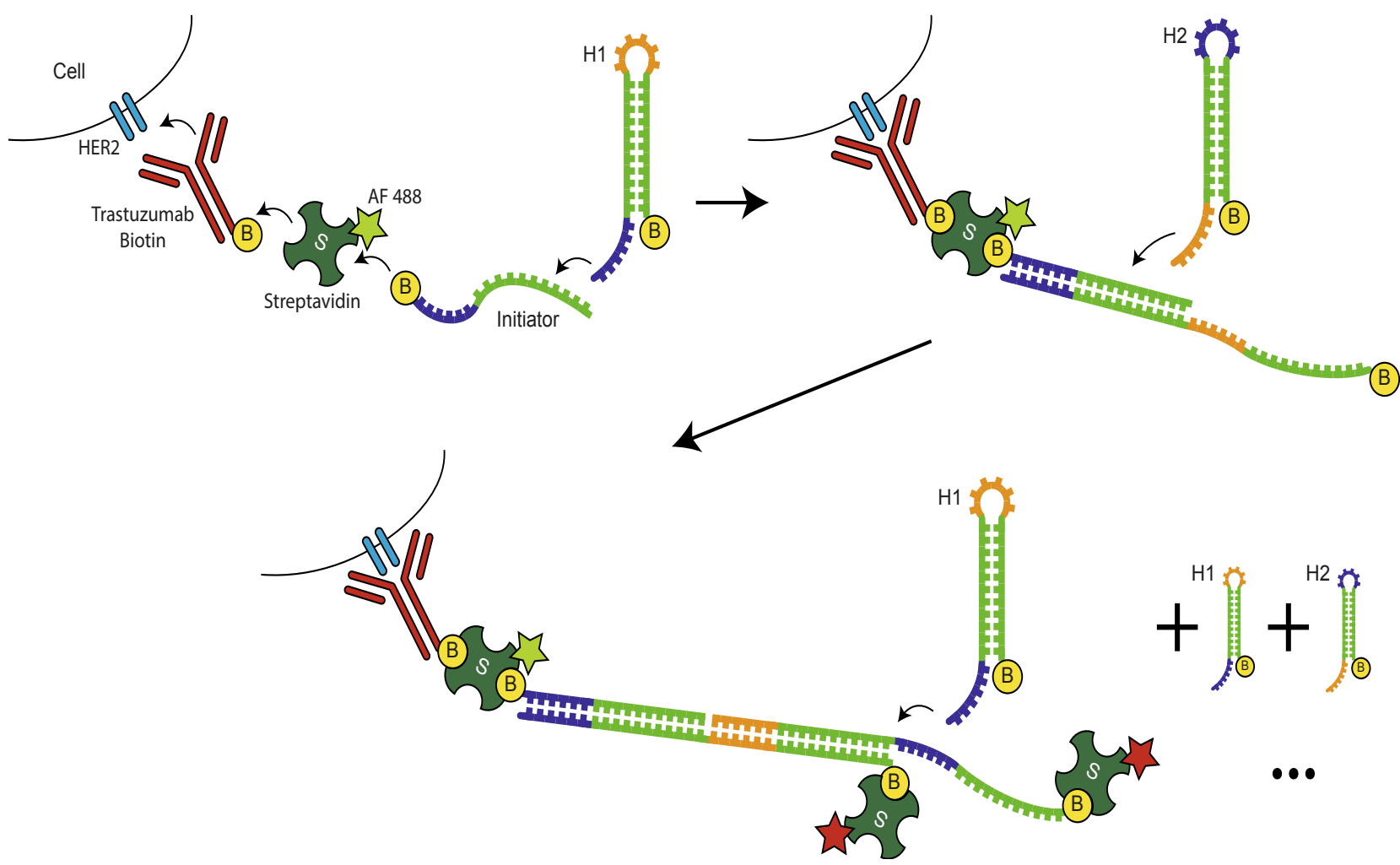

Fig. 3. Targeting/amplification concept. Biotinylated trastuzumab binds to the Her2+ breast cancer cells. The initiator strand (I) attaches to the cell surface via fluorescently-labelled streptavidin and triggers a chain reaction, opens hairpin $\mathrm{H} 1$ and forms a I:H1 complex. In this complex, segment of $\mathrm{H} 1$ can bind to $\mathrm{H} 2$, initiating a branch migration reaction to form a I:H1:H2 complex. 
therapy. For this, we envision DNA molecules with self-assembling capacity based on switchable origami-, ${ }^{[55]}$ DNA bricks-[50] or HCR-[50] approaches. The purpose is to physically encage and 'suffocate' cancer cells through the assembly of a dense peri-cellular DNA net. To render cell killing more efficient, DNA molecules may be decorated with peptides or molecules with direct cytotoxic activity, including membrane destabilizing or apoptosis-inducing peptides. ${ }^{[56]}$ This approach is bio-inspired by the ability of neutrophil granulocytes to trap and kill pathogens by secreting nuclear DNA, also referred to as a neutrophil extracellular trap (NET). ${ }^{[57]}$

\section{Conclusion}

Recent development in the synthesis, characterization and application of bio-inspired materials have opened unprecedented opportunities to address unsolved questions in complex conditions and diseases, including cancer. A long-term goal of the NCCR Center in Bio-Inspired Materials is to identify novel opportunities to apply the knowledge gained to medically relevant questions. The promising results obtained in this project indicate novel strategies to the improved detection and possibly killing of CTCs and DTCs. Translating these strategies into a clinically-useful test or therapy remains, however, a major challenge.

\section{Acknowledgements}

This research is supported by the National Centre of Competence in Research (NCCR) Bio-Inspired Materials, the Swiss National Science Foundation, the Medic Foundation, the Adolphe Merkle Foundation and the University of Fribourg.

Received: November 6, 2018

[1] M. Malvezzi, P. Bertuccio, F. Levi, C. La Vecchia, E. Negri, Ann. Oncol. 2013, 24, 792

[2] C. DeSantis, J. Ma, L. Bryan, A. Jemal, CA Cancer J. Clin. 2014, 64, 52.

[3] a) M. Hergueta-Redondo, J. Palacios, A. Cano, G. Moreno-Bueno, Clin. Transl. Oncol. 2008, 10, 777; b) S. Guiu, S. Michiels, F. Andre, J. Cortes, C. Denkert, A. Di Leo, B. T. Hennessy, T. Sorlie, C. Sotiriou, N. Turner, M. Van de Vijver, G. Viale, S. Loi, J. S. Reis-Filho, Ann. Oncol. 2012, 23, 2997.

[4] M. Colozza, E. de Azambuja, N. Personeni, F. Lebrun, M. J. Piccart, F. Cardoso, Oncologist 2007, 12, 253.

[5] a) W. D. Foulkes, I. E. Smith, J. S. Reis-Filho, N. Engl. J. Med. 2010, 363, 1938; b) D. C. Brady-West, D. A. McGrowder, Asian Pac. J. Cancer Prev. 2011, 12, 2139 .

[6] K. Pantel, R. H. Brakenhoff, Nat. Rev. Cancer 2004, 4, 448

[7] G. Lorusso, C. Ruegg, Semin. Cancer Biol. 2012, 22, 226.

[8] a) J. P. Sleeman, G. Christofori, R. Fodde, J. G. Collard, G. Berx, C. Decraene, C. Ruegg, Semin. Cancer Biol. 2012, 10, 1403; b) E. Marshall, Science 2011, 331, 1540 .

[9] a) T. M. Gorges, K. Pantel, Cancer Immunol. Immunother. 2013, 62, 931; b) Q. Lv, L. Gong, T. Zhang, J. Ye, L. Chai, C. Ni, Y. Mao, Clin. Transl. Oncol. 2016, 18, 322.

[10] K. Pantel, M. R. Speicher, Oncogene 2016, 35, 1216.

[11] S. K. Arya, B. Lim, A. R. Rahman, Lab Chip 2013, 13, 1995.

[12] C. Alix-Panabieres, K. Pantel, Lab Chip 2014, 14, 57.

[13] S. Riethdorf, L. O'Flaherty, C. Hille, K. Pantel, Adv. Drug Deliv. Rev. 2018 , 125,102 .

[14] Z. Zhang, M. R. King, Cell Mol. Bioeng. 2017, 10, 275.

[15] T. M. Gorges, I. Tinhofer, M. Drosch, L. Rose, T. M. Zollner, T. Krahn, O. von Ahsen, BMC Cancer 2012, 12, 178.

[16] S. Rawal, Y. P. Yang, R. Cote, A. Agarwal, Annu. Rev. Anal. Chem. 2017, 10, 321.

[17] a) S. Zheng, H. Lin, J. Q. Liu, M. Balic, R. Datar, R. J. Cote, Y. C. Tai, J. Chromatogr. A 2007, 1162, 154; b) N. V. Cherdyntseva, N. V. Litviakov, E. V. Denisov, P. A. Gervas, E. S. Cherdyntsev, Exp. Oncol. 2017, 39, 2.

[18] a) W. Waheed, A. Alazzam, B. Mathew, N. Christoforou, E. Abu-Nada, $J$. Chromatogr. B Analyt. Technol. Biomed. Life Sci. 2018, 1087-1088, 133; b) S. I. Han, K. H. Han, Anal. Chem. 2015, 87, 10585.

[19] a) M. Zhou, H. Zheng, Z. Wang, R. Li, X. Liu, W. Zhang, Z. Wang, H. Li, Z. Wei, Z. Hu, Theranostics 2017, 7, 4710; b) Y. Qin, X. Yang, J. Zhang, X Cao, Colloids Surf. B Biointerfaces 2017, 151, 39; c) E. Ng, K. Hoshino, X. Zhang, Methods 2013, 63, 266; d) S. W. Lee, K. A. Hyun, S. I. Kim, J. Y. Kang, H. I. Jung, J. Chromatogr. A 2015, 1377, 100.

[20] L. Yu, S. R. Ng, Y. Xu, H. Dong, Y. J. Wang, C. M. Li, Lab Chip 2013, 13, 3163.
[21] a) E. S. Lianidou, A. Markou, Clin. Chem. 2011, 57, 1242; b) K. E. Aaltonen, V. Novosadova, P. O. Bendahl, C. Graffman, A. M. Larsson, L. Ryden, Oncotarget 2017, 8, 45544.

[22] a) S. Bhana, Y. Wang, X. Huang, Nanomedicine (Lond) 2015, 10, 1973; b) L. Chen, L. L. Wu, Z. L. Zhang, J. Hu, M. Tang, C. B. Qi, N. Li, D. W. Pang, Biosens. Bioelectron. 2016, 85, 633.

[23] J. H. Myung, K. A. Tam, S. J. Park, A. Cha, S. Hong, Wiley Interdiscip. Rev. Nanomed. Nanobiotechnol. 2016, 8, 223.

[24] W. Jiang, H. Wang, Y. Cui, Y. Lei, Y. Wang, D. Xu, N. Jiang, Y. Chen, Y. Sun, Y. Zhang, J. Cao, Z. Ke, Int. J. Nanomedicine 2018, 13, 1633.

[25] C. Wang, M. Ye, L. Cheng, R. Li, W. Zhu, Z. Shi, C. Fan, J. He, J. Liu, Z. Liu, Biomaterials 2015, $54,55$.

[26] S. S. Banerjee, V. Khobragade, J. Khandare, Methods Mol. Biol. 2017, 1530 , 271.

[27] P. R. Rauta, P. M. Hallur, A. Chaubey, Sci. Rep. 2018, 8, 2893.

[28] X. Li, B. Chen, M. He, H. Wang, G. Xiao, B. Yang, B. Hu, Biosens. Bioelectron. 2017, 90, 343.

[29] a) J. F. Chen, Y. Zhu, Y. T. Lu, E. Hodara, S. Hou, V. G. Agopian, J. S. Tomlinson, E. M. Posadas, H. R. Tseng, Theranostics 2016, 6, 1425; b) Y. J. Jan, J. F. Chen, Y. Zhu, Y. T. Lu, S. H. Chen, H. Chung, M. Smalley, Y. W. Huang, J. Dong, L. C. Chen, H. H. Yu, J. S. Tomlinson, S. Hou, V. G. Agopian, E. M. Posadas, H. R. Tseng, Adv. Drug Deliv. Rev. 2018 $125,78$.

[30] a) V. Muller, S. Riethdorf, B. Rack, W. Janni, P. A. Fasching, E. Solomayer, B. Aktas, S. Kasimir-Bauer, K. Pantel, T. Fehm, DETECT study group, Breast Cancer Res. 2012, 14, R118; b) B. Aktas, S. Kasimir-Bauer, V. Muller, W. Janni, T. Fehm, D. Wallwiener, K. Pantel, M. Tewes, DETECT study group, BMC Cancer 2016, 16, 522.

[31] W. Haiss, N. T. Thanh, J. Aveyard, D. G. Fernig, Anal. Chem. 2007, 79, 4215.

[32] D. Fey, D. Matallanas, J. Rauch, O. S. Rukhlenko, B. N. Kholodenko, Semin. Cell Dev. Biol. 2016, 58, 96.

[33] M. Schenone, B. C. Furie, B. Furie, Curr. Opin. Hematol. 2004, 11, 272.

[34] G. Bajic, S. E. Degn, S. Thiel, G. R. Andersen, EMBO J. 2015, 34, 2735.

[35] S. Menard, S. M. Pupa, M. Campiglio, E. Tagliabue, Oncogene 2003, 22, 6570.

[36] H. R. Chang, Cancer 2010, 116, 2856

[37] a) Y. Xiao, X. Gao, O. Taratula, S. Treado, A. Urbas, R. D. Holbrook, R. E. Cavicchi, C. T. Avedisian, S. Mitra, R. Savla, P. D. Wagner, S. Srivastava, H. He, BMC Cancer 2009, 9, 351; b) R. Marches, C. Mikoryak, R. H. Wang, P. Pantano, R. K. Draper, E. S. Vitetta, Nanotechnology 2011, 22, 095101.

[38] Q. Ma, Y. Nakane, Y. Mori, M. Hasegawa, Y. Yoshioka, T. M. Watanabe, K. Gonda, N. Ohuchi, T. Jin, Biomaterials 2012, 33, 8486.

[39] G. Arya, M. Vandana, S. Acharya, S. K. Sahoo, Nanomedicine 2011, 7, 859

[40] M. G. Anhorn, S. Wagner, J. Kreuter, K. Langer, H. von Briesen, Bioconjug. Chem. 2008, 19, 2321.

[41] a) F. Dilnawaz, A. Singh, C. Mohanty, S. K. Sahoo, Biomaterials 2010 , 31, 3694; b) N. L. Adolphi, K. S. Butler, D. M. Lovato, T. E. Tessier, J. E. Trujillo, H. J. Hathaway, D. L. Fegan, T. C. Monson, T. E. Stevens, D. L. Huber, J. Ramu, M. L. Milne, S. A. Altobelli, H. C. Bryant, R. S. Larson, E. R. Flynn, Contrast Media Mol. Imaging 2012, 7, 308.

[42] Z. Deng, Z. Zhen, X. Hu, S. Wu, Z. Xu, P. K. Chu, Biomaterials 2011, 32 , 4976.

[43] a) J. F. Hainfeld, M. J. O'Connor, F. A. Dilmanian, D. N. Slatkin, D. J. Adams, H. M. Smilowitz, Br. J. Radiol. 2011, 84, 526; b) B. Van de Broek, N. Devoogdt, A. D'Hollander, H. L. Gijs, K. Jans, L. Lagae, S. Muyldermans, G. Maes, G. Borghs, ACS Nano 2011, 5, 4319.

[44] a) M. Homberger, U. Simon, Philos. Trans. A Math. Phys. Eng. Sci. 2010 368,1405 ; b) E. H. Jeong, G. Jung, C. A. Hong, H. Lee, Arch. Pharm. Res. 2014, 37, 53; c) N. Li, P. Zhao, D. Astruc, Angew. Chem. Int. Ed. 2014, 53 , 1756.

[45] S. K. Libutti, G. F. Paciotti, A. A. Byrnes, H. R. Alexander, Jr., W. E. Gannon, M. Walker, G. D. Seidel, N. Yuldasheva, L. Tamarkin, Clin. Cancer Res. 2010, 16, 6139 .

[46] a) M. Cordeiro, F. Ferreira Carlos, P. Pedrosa, A. Lopez, P. V. Baptista, Diagnostics (Basel) 2016, 6; b) J. Liu, Q. Peng, Acta Biomater. 2017, 55, 13

[47] L. Rodriguez-Lorenzo, S. D. Rafiee, C. Reis, A. Milosevic, T. L. Moore, S. Balog, B. Rothen-Rutishauser, C. Ruegg, A. Petri-Fink, Colloids Surf. B Biointerf. 2018, 171, 579 .

[48] S. A. Smith, R. J. Travers, J. H. Morrissey, Crit. Rev. Biochem. Mol. Biol. 2015, 50, 326

[49] a) B. Sorensen, O. H. Larsen, C. J. Rea, M. Tang, J. H. Foley, C. FengerEriksen, Semin. Thromb. Hemost. 2012, 38, 268; b) J. W. Weisel, R. I. Litvinov, Blood 2013, 121, 1712.

[50] H. M. Choi, V. A. Beck, N. A. Pierce, ACS Nano 2014, 8, 4284

[51] a) Y. Zhang, Z. Chen, Y. Tao, Z. Wang, J. Ren, X. Qu, Chem. Commun. 2015 , 51, 11496; b) G. Zhou, M. Lin, P. Song, X. Chen, J. Chao, L. Wang, Q. Huang, W. Huang, C. Fan, X. Zuo, Anal. Chem. 2014, 86, 7843; c) S. Bi, S. Yue, S. Zhang, Chem. Soc. Rev. 2017, 46, 4281.

[52] a) E. Pailler, M. Oulhen, F. Billiot, A. Galland, N. Auger, V. Faugeroux, C. Laplace-Builhe, B. Besse, Y. Loriot, M. Ngo-Camus, M. Hemanda, C. R. Lindsay, J. C. Soria, P. Vielh, F. Farace, BMC Cancer 2016, 16, 477; b) 
S. Khetani, M. Mohammadi, A. S. Nezhad, Biotechnol. Bioeng. 2018, 115, 2504.

[53] M. Yu, A. Bardia, B. S. Wittner, S. L. Stott, M. E. Smas, D. T. Ting, S. J. Isakoff, J. C. Ciciliano, M. N. Wells, A. M. Shah, K. F. Concannon, M. C. Donaldson, L. V. Sequist, E. Brachtel, D. Sgroi, J. Baselga, S. Ramaswamy, M. Toner, D. A. Haber, S. Maheswaran, Science 2013, 339, 580.

[54] a) A. Giordano, H. Gao, S. Anfossi, E. Cohen, M. Mego, B. N. Lee, S. Tin, M. De Laurentiis, C. A. Parker, R. H. Alvarez, V. Valero, N. T. Ueno, S. De Placido, S. A. Mani, F. J. Esteva, M. Cristofanilli, J. M. Reuben, Mol. Cancer Ther. 2012, 11, 2526; b) H. Schneck, B. Gierke, F. Uppenkamp, B. Behrens, D. Niederacher, N. H. Stoecklein, M. F. Templin, M. Pawlak, T. Fehm, H. Neubauer, D. Disseminated Cancer Cell Network, PLoS One
2015, 10, e0144535; c) S. Wu, S. Liu, Z. Liu, J. Huang, X. Pu, J. Li, D. Yang, H. Deng, N. Yang, J. Xu, PLoS One 2015, 10, e0123976.

[55] J. K. Daljit Singh, M. T. Luu, A. Abbas, S. F. J. Wickham, Biophys. Rev. 2018, 10, 1283.

[56] a) K. Numata, D. L. Kaplan, Biomacromolecules 2010, 11, 3189; b) L. Stassen, H. Huismans, J. Theron, Arch. Virol. 2011, 156, 711; c) H. Wang, H. Wang, J. Liang, Y. Jiang, Q. Guo, H. Peng, Q. Xu, Y. Huang, Mol. Pharm. 2014, 11, 3352.

[57] V. Delgado-Rizo, M. A. Martinez-Guzman, L. Iniguez-Gutierrez, A. GarciaOrozco, A. Alvarado-Navarro, M. Fafutis-Morris, Front. Immunol. 2017, 8 , 81. 